\title{
Genetic variability in common wheat germplasm based on coefficients of parentage
}

\author{
Fernanda Bered $^{1}$, José F. Barbosa-Neto ${ }^{2}$ and Fernando I.F. de Carvalho ${ }^{3}$ \\ ${ }^{I}$ Departamento de Genética, Instituto de Biociências, UFRGS. Porto Alegre, RS, Brazil. \\ ${ }^{2}$ Departamento de Plantas de Lavoura, Faculdade de Agronomia, UFRGS. Porto Alegre, RS, Brazil. \\ ${ }^{3}$ Departamento de Fitotecnia, Faculdade de Agronomia "Eliseu Maciel”, Pelotas, RS, Brazil.
}

\begin{abstract}
The characterization of genetic variability and an estimate of the genetic relationship among varieties are essential to any breeding program, because artificial crosses among less similar parents allow a larger segregation and the combination of different favorable alleles. Genetic variability can be evaluated in different ways, including the Coefficient of Parentage (COP), which estimates the probability of two alleles in two different individuals being identical by descent. In this study, we evaluated the degree of genetic relationship among 53 wheat genotypes, and identified the ancestor genotypes which contributed the most to the current wheat germplasm, as a prediction of the width of the genetic base of this cereal. The results revealed a mean COP of 0.07 and the formation of 22 similarity groups. The ancestor genotypes Ciano 67 and Mentana were those which contributed the most to the current wheat germplasm. According to the COP analyses, the genetic base of wheat rests on a small number of ancestral genotypes.
\end{abstract}

Key words: COP, genetic base, gene pool, Triticum aestivum L.

Received: January 27, 2000; accepted: April 26, 2002.

\section{Introduction}

Genetic variability is required to achieve genetic gains in a breeding program. Estimation of genetic variability among genotypes can be based on qualitative and quantitative traits (Spagnoletti-Zeuli and Qualset, 1987; Souza and Sorrells, 1991; van Beuningen and Busch, 1997b), molecular markers (Smith and Smith, 1988; Barbosa-Neto et al., 1996; Cao et al., 1998; Fahima et al., 1999), and coefficient of parentage (Martin et al., 1991; Barbosa-Neto et al., 1996; Mercado et al., 1996; van Beuningen and Busch, 1997a; Burkhamer et al., 1998). The coefficient of parentage (COP) measures the probability that alleles of two individuals are identical by descent, and has been used extensively to indirectly assess variability within gene pools (Burkhamer et al., 1998). A pair of individuals with a high COP probably share a greater number of identical alleles. A cross between them will probably produce $\mathrm{a}_{2}$ generation with a reduced number of allelic combinations, and will be expected to show reduced variability in segregating generations (Beer et al., 1995). COP analysis can be applied to an estimation of genetic diversity among cultivars

Send correspondence to F. Bered. Departamento de Genética, Instituto de Biociências, UFRGS, Av. Bento Gonçalves, 9500, PR 43323, 91501-970 Porto Alegre, RS, Brazil. E-mail: fbered@ portoweb.com.br. and parental germplasm, predicting breeding behavior of the progeny of crosses, summarizing regional crop diversity, identifying parents that have contributed to yield improvements, and searching trends in genetic diversity over time and space (Kim and Ward, 1997; Souza et al., 1998).

Estimation of genetic variability by means of COP requires detailed pedigree data. Once pedigrees are known, the coefficient of parentage may be used as an estimate of genetic similarity (Cox et al., 1985). In this way, COP can be used as an index of relationship. COP values range from zero, where cultivars are completely unrelated, to one, where two cultivars have all alleles in common (Martin et al., 1991). The use of a COP data matrix can cluster genotypes and produce genealogically similar groups. These groups can be used to maximize heterozygosity in the progeny of crosses and to predict heterosis (Barbosa-Neto et al., 1996; Souza et al., 1998).

The objective of this work was to examine the genetic variability of wheat germplasm used in genetic improvement programs in the south of Brazil. We also wished to evaluate the degree of genetic relationship among genotypes, so as to predict the extent of the genetic base of wheat. Finally, we also identified the ancestral genotypes that contributed most to the genetic pool of Brazilian wheat. The aim of this approach was to place genotypes into groups of genetic similarity, to aid the amplification of genetic variation in artificial crosses. 


\section{Materials and Methods}

Fifty-three wheat genotypes, classified by commercial release year, were included in this study (Table I). The sample included inbred lines and cultivars from different origins, chosen based on their importance, either commercial or as parents. Pedigrees were obtained from Zeven and Zeven-Hissink (1976), Zeven and Reiner (1991), Graingenes Database, and additional information was provided by wheat breeders. The pedigree of a genotype was traced back to its ancestors' parents or landraces. Coefficients of parentage (COP) were computed for all pairwise combinations of genotypes from pedigree information, according to Barbosa-Neto et al. (1996). In using this method, it was assumed that: 1) an inbred plant received half its genes from each parent; 2) parents used in crosses were homozygous and homogeneous; 3 ) ancestors for which no pedigree information was available were unrelated $(\mathrm{COP}=$ $0.00)$;) the COP value between a cultivar and a selection from that cultivar was 0.75 . The genotypes were included in a relationship matrix and were grouped using the Un- weighted Pair Group Method of clustering (NT-SYS software for PC). The groups were generated starting from the value 0.125 (grandparent / grandchild relationship). Mean COP values within and between clusters were computed, after deleting clusters with a single entry. The ancestors' parents were chosen based on literature and information obtained from wheat breeders, and the contribution to wheat germplasm was computed considering the frequency of genotypes with COP above 0.125 (ancestors $\mathrm{x}$ genotype).

\section{Results and Discussion}

The mean COP for all genotypes analyzed was 0.07 , ranging from 0 to 0.82 (BR35 x IAC5), a value close to that obtained for wheat by Barbosa-Neto et al. (1996) . Similar studies have shown a mean COP around 0.20 (Autrique et al., 1996; Kim and Ward, 1997; Souza et al., 1998). The violation of $\mathrm{COP}$ assumptions results in an underestimation of the true values. The assumption that genotypes without pedigree information were unrelated $(\mathrm{COP}=0.00)$ contrib-

Table I - Group (Gr), year of release and origin of evaluated hexaploid wheat.

\begin{tabular}{|c|c|c|c|c|c|c|c|}
\hline Genotype & $\mathrm{Gr}$ & Year & Origin & Genotype & Gr & year & Origin \\
\hline Caldwell (CAL) & 1 & 1981 & U.S.A & BR18 & 8 & 1986 & Brazil \\
\hline Embrapa 15 (EMB15) & 1 & 1992 & Brazil & $\mathrm{BR} 23$ & 8 & 1987 & Brazil \\
\hline CEP 14 & 2 & 1985 & Brazil & CEP24 & 9 & 1992 & Brazil \\
\hline CEP11 & 3 & 1984 & Brazil & CNT10 & 9 & 1977 & Brazil \\
\hline BH1146 & 4 & 1955 & Brazil & Cotiporã (COT) & 9 & 1965 & Brazil \\
\hline BR32 & 4 & 1988 & Brazil & Trintecinco (TRI) & 9 & 1936 & Brazil \\
\hline BR35 & 4 & 1989 & Brazil & BR43 & 10 & 1991 & Brazil \\
\hline E7414 & 4 & 1967 & Brazil & Jacuí (JAC) & 10 & 1973 & Brazil \\
\hline Frontana (FRO) & 4 & 1943 & Brazil & RS8 & 10 & 1991 & Brazil \\
\hline IAC5 & 4 & 1966 & Brazil & Bezoataja (BEZ) & 11 & 1967 & Russia \\
\hline IAS20 & 4 & 1963 & Brazil & OC22 & 11 & 1992 & Brazil \\
\hline Nobre (NOB) & 4 & 1969 & Brazil & $\mathrm{S} 8020$ & 11 & 1984 & Brazil \\
\hline OC8148 & 4 & 1984 & Brazil & OC935 & 12 & $*$ & Brazil \\
\hline OC958 & 5 & $*$ & Brazil & OC94117 & 12 & $*$ & Brazil \\
\hline PF79547 & 5 & 1981 & Brazil & OC952 & 12 & $*$ & Brazil \\
\hline BR15 & 6 & 1985 & Brazil & CEP27 & 13 & 1995 & Brazil \\
\hline BR34 & 6 & 1989 & Brazil & Embrapa 16 (EMB16) & 14 & 1992 & Brazil \\
\hline IAS54 & 6 & 1970 & Brazil & RS1 & 15 & 1984 & Brazil \\
\hline Anahuac 75 (ANA) & 7 & 1981 & Mexico & Bonaerense (BONA) & 16 & 1987 & Argentina \\
\hline Cajeme 71 (CAJ) & 7 & 1971 & Mexico & BR38 & 17 & 1990 & Brazil \\
\hline Embrapa 24 (EMB24) & 7 & 1993 & Brazil & OC953 & 18 & $*$ & Brazil \\
\hline Las Rosas Inta (LRI) & 7 & 1983 & Argentina & OC9941 & 18 & $*$ & Brazil \\
\hline OC16 & 7 & 1989 & Brazil & Peladinho (PEL) & 19 & 1978 & Brazil \\
\hline OC18 & 7 & 1990 & Brazil & Embrapa 40 (EMB40) & 20 & 1995 & Brazil \\
\hline Sonora 64 (SON) & 7 & 1975 & Mexico & BR37 & 21 & 1990 & Brazil \\
\hline Alondra 4546 (ALO) & 8 & 1980 & Mexico & OC9511 & 22 & $*$ & Brazil \\
\hline BR14 & 8 & 1985 & Brazil & & & & \\
\hline
\end{tabular}

\footnotetext{
* - inbred lines obtained in 1995.
} 
uted to the low value of the mean COP, since there were several genotypes with no pedigree information. A specific example was reported by Souza et al. (1998), showing that spring wheat cultivars with the least documented pedigrees had low similarity to other clusters. The contribution of deviation from these assumptions may vary between crosses, but should be more significant, as individuals become more related (Burkhamer et al., 1998). According to van Beuningen and Busch (1997a), variability may be underestimated, because the cultivars were assumed to be homogeneous and homozygous, and the ancestors were not pure lines.

Cluster analysis revealed 22 groups of related genotypes (Table I), constituting half of only one genotype and half of at least two genotypes. The groups with more than one genotype were used to estimate the mean COP within and between groups (Table II). As expected, the results showed the COP to be high within the same groups (mean=
0.26 ) and low among the groups $($ mean $=0.05)$. Group 10 (BR43, Jacuí and RS8) had the highest mean COP (0.43), revealing a strong relationship among these varieties. Groups 9 and 10 were the most closely related ones $(\mathrm{COP}=0.15)$.

The ancestors' contribution analysis (Table III) revealed that the one that contributed most to the wheat gene pool $(34 \%)$ was the ancestor Ciano 67 , followed by Mentana (32\%). These two cultivars may have had significant general combining ability, and may have expressed genes that contributed to wheat stability and adaptability. On the other hand, ancestors Turkey, Mediterranean, Norin 10 and Siete Cerros were only included in the gene pool since 1970. Before 1970, genotypes Red Egyptian and Alfredo Chaves 6 had greater importance. According to Martin et al. (1991), regional gene pools are often based on a limited number of original ancestors, these original ancestors remaining the core of the present germplasm base. Moreover, breeders have favored either backcrossing or

Table II - Mean coefficient of parentage (COP) within (on diagonal) and between (below diagonal) genotype groups.

\begin{tabular}{|c|c|c|c|c|c|c|c|c|c|c|c|}
\hline & \multicolumn{11}{|c|}{ Groups } \\
\hline & 1 & 4 & 5 & 6 & 7 & 8 & 9 & 10 & 11 & 12 & 18 \\
\hline 1 & 0.24 & & & & & & & & & & \\
\hline 4 & 0.02 & 0.23 & & & & & & & & & \\
\hline 5 & 0.02 & 0.12 & 0.19 & & & & & & & & \\
\hline 6 & 0.02 & 0.10 & 0.10 & 0.31 & & & & & & & \\
\hline 7 & 0.02 & 0.08 & 0.08 & 0.08 & 0.24 & & & & & & \\
\hline 8 & 0.02 & 0.08 & 0.08 & 0.08 & 0.12 & 0.29 & & & & & \\
\hline 9 & 0.02 & 0.06 & 0.06 & 0.06 & 0.06 & 0.06 & 0.25 & & & & \\
\hline 10 & 0.02 & 0.06 & 0.06 & 0.06 & 0.06 & 0.06 & 0.15 & 0.43 & & & \\
\hline 11 & 0.02 & 0.05 & 0.05 & 0.05 & 0.05 & 0.05 & 0.05 & 0.05 & 0.29 & & \\
\hline 12 & 0.02 & 0.05 & 0.05 & 0.05 & 0.05 & 0.05 & 0.05 & 0.05 & 0.06 & 0.27 & \\
\hline 18 & 0.02 & 0.0 & 0.0 & 0.0 & 0.0 & 0.0 & 0.0 & 0.0 & 0.0 & 0.0 & 0.13 \\
\hline
\end{tabular}

Table III - Ancestral parents of wheat germplasm: mean coefficient of parentage (COP) and percentage of contribution from two periods.

\begin{tabular}{lccccc}
\hline Ancestral & Origin & $\begin{array}{c}\text { Mean } \\
\text { COP }\end{array}$ & $\begin{array}{c}\text { Total } \\
\text { contribution (\%) }\end{array}$ & $\begin{array}{c}\text { Contribution } \\
1930-1970(\%)\end{array}$ & $\begin{array}{c}\text { Contribution } \\
\text { 1971-1999 (\%) }\end{array}$ \\
\hline Turkey & Ukraine & 0.05 & 6 & 0 & 6 \\
Mediterranean & U.S.A & 0.03 & 4 & 0 & 4 \\
Steinwedel & S.Africa & 0.009 & 0 & 0 & 0 \\
Red Egyptian & Africa & 0.02 & 4 & 4 & 0 \\
Alfredo Chaves 6 & Brazil & 0.03 & 6 & 4 & 0 \\
Polyssu & Brazil & 0.06 & 11 & 7 & 4 \\
Kenya 58 & Kenya & 0.04 & 11 & 7 & 4 \\
Norin 10 & Japan & 0.04 & 8 & 0 & 8 \\
Mentana & Italy & 0.09 & 32 & 13 & 19 \\
Siete Cerros & Mexico & 0.06 & 9 & 0 & 9 \\
Ciano 67 & Mexico & 0.12 & 34 & 6 & 28 \\
Colonias & Brazil & 0.05 & 14 & 7 & 7 \\
Combate & Brazil & 0.05 & 13 & 11 & 2 \\
\hline
\end{tabular}


repeated cycles of mating to adapted germplasm for the introduction of new germplasm into wheat gene pool (Mercado et al., 1996).
Analyzing the pedigrees and COP of each group, it can be seen that groups can be determined for some ancestors (Table IV). The fact that only a few representative an-

Table IV - Pedigrees and groups of hexaploid wheat genotypes evaluated.

\begin{tabular}{|c|c|c|c|}
\hline Genotype & Pedigree & Gr. & Ancestors \\
\hline CAL & $\mathrm{FZ} / / \mathrm{H} / \mathrm{HU}$ & 1 & Med \\
\hline EMB15 & CNT10/BR35//PF75172/Sel.TON 75-59 & 1 & Med \\
\hline BH1146 & $\mathrm{PG} 1 / / \mathrm{FT} / \mathrm{MT}$ & 4 & Mt; Pol; Cas; K \\
\hline BR32 & IAS60/IN//IAS62/3/ALONDRA SIB/4/IAS59 & 4 & Mt; Pol; Cas; K \\
\hline BR35 & IAC $5 * 2 / 3 / \mathrm{CNT} 7 * 3 / \mathrm{LD} / / \mathrm{IAC} 5 / \mathrm{HADDEN}$ & 4 & Mt; Pol; Cas; K \\
\hline E7414 & IAS20//IAS20/INIA66 & 4 & Mt; Pol; Cas; K \\
\hline FRO & $\mathrm{FT} / \mathrm{MT}$ & 4 & Mt; Pol; Cas; K \\
\hline IAC5 & FN/K58//PG1 & 4 & Mt; Pol; Cas; K \\
\hline IAS20 & $\mathrm{CAS} / / \mathrm{FN} / \mathrm{K} 58$ & 4 & Mt; Pol; Cas; K \\
\hline NOB & CO 824-51/YT 54//CO 296-52 & 4 & Mt; Pol; Cas; K \\
\hline OC8148 & IAC5/ALD SIB & 4 & Mt; Pol; Cas; K \\
\hline OC958 & LD/6/KVZ/LD*6/AGE/3/LD*6/KUZ//LD*6/WTP/4/IAS63/ALD/5/ & 5 & Mt; Cia \\
\hline PF79547 & (IAS58-IAS55/ALD “s”/IAC5) ALD “s” & 5 & Mt; Cia \\
\hline BR15 & IAS54*2/TK80//PF 69193 & 6 & Mt; Cia \\
\hline BR34 & ALZ110/2*IAS54/6/TP/4/TZPP /SON64/ / NAPO /3/ CIA/5/PF6968 & 6 & Mt; Cia \\
\hline IAS54 & IAS16/4/N10 B17/Y53//Y50/3/KT 54B & 6 & Mt; Cia \\
\hline ANA & II 12300//LR 64/8156/3/NT67 & 7 & Cia; Tky; N10; Mt; SC \\
\hline CAJ & CIA67/3/SON64/KR//SIETE CIERROS & 7 & Cia; Tky; N10; Mt; SC \\
\hline EMB24 & SEL.TON/PF79763/3/NBOZU/LD*3//B7902 & 7 & Cia; Tky; N10; Mt; SC \\
\hline LRI & $\mathrm{KLAT} / / \mathrm{INIA} / \mathrm{BB} / 4 / \mathrm{NP} 876 / \mathrm{PJ} / \mathrm{CAL} / 3 / \mathrm{BB}$ & 7 & Cia; Tky; N10; Mt; SC \\
\hline OC16 & SISKIN SIB/VEERY SIB & 7 & Cia; Tky; N10; Mt; SC \\
\hline OC18 & KAVRAZ/BUHO SIB//KN/BB & 7 & Cia; Tky; N10; Mt; SC \\
\hline SON & YT94/N 10b//2*Y54 & 7 & Cia; Tky; N10; Mt; SC \\
\hline ALO & D6301/NAI60//WEIQUE/RED MACE/3/CIA*2/CHR & 8 & Cia; Cas; Tky; N10 \\
\hline BR14 & IAS63/ALONDRA SIB//GTO/LV & 8 & Cia; Cas; Tky; N10 \\
\hline BR18 & ALONDRA SIB & 8 & Cia; Cas; Tky; N10 \\
\hline $\mathrm{BR} 23$ & CC/ALONDRA SIB/3/IAS54/COP//CNT8 & 8 & Cia; Cas; Tky; N10 \\
\hline CEP24 & BR3/CEP7887//CEP7775/CEP11 & 9 & Cas; Cte \\
\hline CNT10 & IAS46/IAS49//IAS46/TK66 & 9 & Cas; Cte \\
\hline COT & VP*2/E NA101 & 9 & Cas; Cte \\
\hline TRI & $\mathrm{AC} 3 / \mathrm{AC} 4$ & 9 & Cas; Cte \\
\hline BR43 & PF833007/JACUI & 10 & Mt \\
\hline $\mathrm{JAC}$ & $\mathrm{S} 8 / \mathrm{TP}$ & 10 & Mt \\
\hline RS8 & CNT10/BURGAS//JACUI & 10 & Mt \\
\hline BEZ & LUT17/SKOROSPELKA2 & 11 & Tky; Cia; Cas \\
\hline OC22 & KNS/BB//CJ SIB/3/ALONDRA SIB/4/RS3 & 11 & Tky; Cia; Cas \\
\hline S8020 & COXILHA/KAVRAZ & 11 & Tky; Cia; Cas \\
\hline OC935 & BTU/PG868 & 12 & $\mathrm{Mt} ; \mathrm{Cia} ; \mathrm{SC}$ \\
\hline OC94117 & URES80/PG868 & 12 & Mt; Cia; SC \\
\hline OC952 & SERI/PG868 & 12 & $\mathrm{Mt}$; Cia; SC \\
\hline OC953 & PG864/GEN & 18 & * \\
\hline OC9941 & GEN/2*PF83144 & 18 & * \\
\hline
\end{tabular}

* - There were no representative ancestors of this group.

Cas-Colonias; Cia -Ciano; Cte - Combate; K - Kenya58; Med-Mediterranean; Mt - Mentana; N10 - Norin10; Pol - Polyssu; SC- Siete Cerros; Tky Turkey. 
cestors of the groups were observed suggests again that this set of wheat germplasm reflects a narrow genetic base.

Comparing wheats from USA, Canada and Mexico, based on average COP, those from Mexico were more diverse than those from breeding programs in the USA and Canada (van Beuningen and Busch, 1997a). Despite the relatively low genetic similarity estimates based on COP in our work, we concluded that Brazilian germplasm was developed from a narrow genetic background, as revealed by the small number of ancestors investigated.

\section{Conclusions}

Genetic variability was detected among the genotypes evaluated. Based on the examined samples, Ciano 67 and Mentana were the most important genotypes in the constitution of the current wheat germplasm. Moreover, the genetic base of wheat germplasm is constituted by a restricted number of ancestor genotypes. Coefficient of Parentage (COP) analysis was effective in evaluating the variability and genetic base of wheat.

\section{References}

Autrique E, Nachit MM, Monneveux P, Tanksley SD and Sorrells ME (1996) Genetic diversity in Durum Wheat based on RFLPs, morphophysiological traits, and coefficient of parentage. Crop Sci. 36:735-742.

Barbosa-Neto JF, Sorrells ME and Cisar G (1996) Prediction of heterosis in wheat using coefficient of parentage and RFLP-based estimates of genetic relationship. Genome. 39:1142-1149.

Beer SC, Souza E and Sorrells ME (1995) Prediction of genotype performance from ancestors relationship in oat. Crop Sci. 35:69-73.

Burkhamer RL, Lanning SP, Martens RJ, Martin JM and Talbert LE (1998) Predicting progeny variance from parental divergence in Hard Red Spring wheat. Crop Sci. 38:243-248.

Cao W, Hucl P, Scoles G and Chibbar RN (1998) Genetic diversity within spelta and macha wheats based on RAPD analysis. Euphytica. 104: 181-189.
Cox TS, Kiang YT, Gorman MB and Rodgers DM (1985) Relationship between coefficient of parentage and genetic similarity indices in the soybean. Crop Sci. 25:529-532.

Fahima T, Sun GL, Beharav A, Krugman T, Beiles A and Nevo E (1999) RAPD polymorphism of wild emmer wheat populations, Triticum dicoccoides, in Israel. Theor. Appl. Gen. 98:434-447.

Kim HS and Ward RW (1997) Genetic diversity in Eastern U.S. soft winter wheat (Triticum aestivum L. em. Thell.) based on RFLPs and coefficient of parentage. Theor. Appl. Genet. 94:472-479.

Martin JM, Blake TK and Hockett EA (1991) Diversity among North American Spring Barley cultivars based on coefficient of parentage. Crop. Sci. 31:1131-1137.

Mercado LA, Souza E and Kephart KD (1996) Origin and diversity of North American hard spring wheats. Theor. Appl. Genet. 93:593-599.

Smith JSC and Smith OS (1988) Associations among inbred lines of maize using electrophoretic, chromatographic, and pedigree data. Theor. Appl. Genet. 76:39-44.

Souza E and Sorrells ME (1991) Relationships among 70 North American oat germplasms: I. Cluster analysis using quantitative characters. Crop Sci. 31:599-605.

Souza E, Fox PN and Skovmand B (1998) Parentage analysis of International Spring Wheat Yield Nurseries 17 to 27. Crop Sci. 38:337-341.

Spagnoletti-Zeuli PLS and Qualset CO (1987) Geographical diversity for quantitative spike characters in a world collection of durum wheat. Crop Sci. 27:235-241.

Van Beuningen LT and Busch RH (1997a) Genetic diversity among North American spring wheat cultivars: I. Analysis of the coefficient of parentage matrix. Crop Sci. 37:570-579.

Van Beuningen LT and Busch RH (1997b) Genetic diversity among North American spring wheat cultivars: III. Cluster analysis based on quantitative morphological traits. Crop Sci.37:981-988.

Zeven A and Reiner L (1991) Genealogies of 3200 wheat varieties. Institute of Plant Breeding-I.v.P., Agricultural University. Wageningen, The Netherlands. Crop Husbandry, Technical University Munich, Germany. 79 pp.

Zeven A and Zeven-Hissink NC (1976) Genealogies of 14000 wheat varieties. The Netherlands Cereal Centre, Wageningen, International Maize and Wheat Improvement Center, Mexico. 121 pp. 